Child Abuse Linked to Accusations of "Possession" and "Witchcraft"

Eleanor Stobart 
Research Report

No 750

\title{
Child Abuse Linked to Accusations of "Possession" and "Witchcraft"
}

\author{
Eleanor Stobart
}

The views expressed in this report are the authors' and do not necessarily reflect those of the Department for Education and Skills. 
INTRODUCTION

Background

Terms

Aims

Definitions

Approach

Identifying cases

CASE ANALYSIS

Cases identified per year

Victims' age and gender

Identifying agency

Cases by region

Origin or background

Period of UK residency

Religion

Places of worship involved

Family structure

A child with a difference

Accusation

Types of abuse

Outcomes

FINDINGS

Family structure

Scapegoats

A child with a difference

Disability

Types of abuse

Outcomes

Case handling

Migration

Mental health

Religious and spiritual beliefs

Movement of children

GOOD PRACTICE

Early intervention

Specialist training and support

A practical and culturally based approach

Child protection in places of worship

CONCLUSION

RECOMMENDATIONS 


\section{SUMMARY}

This report concerns the frequency and severity of child abuse linked to accusations of "possession" and "witchcraft". It identifies key features common to these cases, draws conclusions and makes recommendations.

The report is based on desk research and discussions with social workers, school teachers, police officers, voluntary workers and others who had knowledge of aspects of the subject. An important feature has been collecting and examining reports of cases that occurred since January 2000 , analysing the often limited information recorded and drawing conclusions from this material.

The belief in "possession" and "witchcraft" is widespread. The UK is not alone in seeing cases of this nature; cases have been reported worldwide. The children discussed in this report came from a variety of backgrounds including African, South Asian and European.

Seventy-four cases of abuse clearly linked to accusations of "possession" and "witchcraft" were identified. To safeguard against double-counting, only cases for which there were identifying factors were analysed. Therefore, this report only analyses thirty-eight of these cases. It should be noted that prior to enquiries only fourteen cases were clearly identified and new cases were being reported right up to the date of publication of this report.

The number of cases of child abuse linked to accusations of "possession" and "witchcraft" so far identified is small compared to the total number of children abused each year.

In the year to 31 March 2005, 30,700 children were placed on child protection registers in England. There were 72,100 child protection enquiries in England in the year to 31 March 2004.

The abuse in question occurs when an attempt is made to "exorcise" the child. The abuse consists of severe beatings and other premeditated cruelties such as starving, burning and isolating the child. The perpetrators are usually carers often not the natural parents - and the abuse usually occurs in the household where the child lives. As a last resort the child may be abandoned overseas. Their further history is not known.

There appear to be common features between cases, for instance, a child being scapegoated, family structure and disability. By recognising these patterns and links it may be possible to identify children at risk early and prevent cases from escalating.

The recommendations address gathering better information about cases, drawing up guidance about handling cases, monitoring the movement of children and protecting children in places of worship. 


\section{INTRODUCTION}

\section{Background}

Recently there have been two very high profile cases (Victoria Climbié and Child B) where adults believed that a child in their care was a "witch" or "possessed by evil spirits". In an attempt by the carers to remove the "evil spirit", these children were subjected to serious physical and emotional abuse.

During the investigation of the Child B case, it became apparent that there were other cases where this belief appeared to contribute to child abuse.

This led the Metropolitan Police Service (MPS) to set up a working group, Project Violet, to assess the impact it might have on child protection in London. The initial project was confined to the London area and focused on Congolese and Angolan communities.

Further work has been undertaken by the MPS in the form of the Community Partnership Pilot Project. This was part of the MPS strategy to strengthen its child protection response in the wake of the tragic death of Victoria Climbié. This pilot project consulted African and Asian communities in two parts of London about child protection issues. One subject discussed was "possession in children" and it was clear that the belief that children can be "possessed" was widespread across both communities and could in some circumstances, lead to abuse.

\section{Terms}

The Department for Education and Skills (DfES) commissioned this report in an attempt to gauge the extent, nature and geographical spread of child abuse linked to accusations of "possession" or "witchcraft". Although "possession" and "witchcraft" may affect adults, this report is specifically concerned with child abuse. The time available for the research and writing of the report was four months (September to December 2005).

\section{Aims}

The purpose of this report is:

- To establish the scale and extent of child abuse related to accusations of "possession" or "witchcraft"

- To produce an analysis of the key features of known cases

- To identify good practice in child protection and community involvement across the public sector, non-governmental organisations, voluntary organisations and faith-based organisations

- To place the issue in an international context. 


\section{INTRODUCTION}

\section{Definitions}

There was no common language for many of the concepts in this report. We asked people involved in our research what language was appropriate to describe the beliefs that might contribute to this form of abuse. Terms suggested included ritual abuse, kindoki, ndoki, child sorcerers, the spirit world, the evil eye, djinns, black magic, voodoo, obeah, possession and witchcraft.

The term ritual abuse may be associated with "satanic ritual abuse"; (ki)ndoki is specific to certain regions of Africa including Congo, Angola and the Democratic Republic of the Congo (DRC); "the spirit world" is a vague term and could have numerous different meanings. The other terms seem to be either quite specific to certain cultures or rather vague.

The most widely acceptable terms across faith-based organisations, nongovernmental organisations and the public sector are "possession by evil spirits" or "witchcraft". For the purposes of this report, the term "possession" means an evil force has entered a child and is controlling him or her and the term "witch" means a child who is able to use evil forces to harm others. In either case, these are genuine beliefs held by families and often the children themselves. When families hold this belief about a child they are terrified of him or her, they feel that everything is under threat - even their lives.

Although these terms are not entirely satisfactory, they are the least misleading and the most widely understood.

It is recognised that these are very specific and disputed uses of these terms. "Possession" can be understood to include being taken over by a force for good (e.g. the Holy Spirit). Equally, for both practitioners of "Wicca" and "witchdoctors" the term "witch" can mean a person who is able to use good or evil forces for good or evil purposes.

We came across three common terms for getting rid of the "evil spirit" - these were "praying for children", "deliverance" and "exorcism". Colloquially "exorcism" was the most all-encompassing term understood by most people we spoke to during our research. The Collins English Dictionary defines exorcism as "expelling, or attempting to expel, one or more evil spirits from a person or place believed to be possessed or haunted, by prayers, adjurations and religious rites". There is a range of behaviour associated with "exorcism" from praying for a child while he or she is not present through to "beating the devil out of the child".

For the purposes of this report a child is considered to be a young person under the age of 18 years as defined by the Children Act 1989. 


\section{INTRODUCTION}

The recognised categories of child abuse as set out in "What to do if you are worried a child is being abused"1 have been adopted. These categories are:

- Physical

- Emotional

- Sexual

- Neglect

In the majority of cases discussed in this report the types of abuse seen are physical abuse involving hitting, beating and burning. Emotional abuse, isolation and neglect were features of almost all cases. Some abuse involved rubbing chilli peppers and other substances on the child's genitals, which may be reported as a sexual assault.

For the purposes of this report a case is defined as a household where a child or children were abused following an accusation of "possession" or "witchcraft".

\section{Approach}

This report is not a formal, academic study of religious or spiritual beliefs. It reviews the practical implications of beliefs about "possession" and "witchcraft" for public sector organisations concerned with child protection and how this may affect public policy.

The research followed a conventional pattern of desk research, interviews and case analysis.

The desk research covered specialist journals together with Internet and written material from both the United Kingdom and overseas. Of particular interest were Dr Filip de Boeck's work on child sorcerers in the Democratic Republic of the Congo (DRC) ${ }^{2}$ and a report by Save the Children UK also on Child Sorcerers in the $\mathrm{DRC}^{3}$. The latter report is the culmination of two years work studying 2000 cases of children who had been accused of "witchcraft" in DRC. The report identified the reasons behind these accusations in the context of the DRC and there are some similarities to incidents in England.

\footnotetext{
${ }^{1}$ What to do if you are worried a child is being abused, Department of Health, 2003

2 “Deuxième Monde et Ses Enfants Sorciers en DRC" - Politique Africaine, 2000 [80] 32 Dr Filip de Boeck, University of Leuven, Belgium

3 “Enfants Sorciers en République Démocratique de Congo" September 2005, Javier Aguila Molinas, Save the Children UK
} 


\section{INTRODUCTION}

A large part of the work was conducted through public sector professionals in police, social care, health, education and to a lesser extent other public sector agencies such as immigration, benefits and housing.

We also consulted other interested parties in the UK and Europe including faithbased organisations and non-governmental organisations. We talked to academics specialising in theology, anthropology and transcultural psychiatry.

\section{Identifying cases}

There were difficulties identifying cases for several reasons. This was partly due to the way in which police databases can be searched because cases are recorded by the type of crime e.g. assault, rather than the circumstances surrounding the crime. Other public sector organisations have no means of searching their database records by using key words. It became apparent after analysing the cases that schools were the most useful source in identifying cases and providing detailed information about the children.

We made inquiries of a number of non-governmental organisations and faith based organisations. Their involvement with families was not always on a formal basis and therefore they may not have had access to full records or did not maintain their own case files.

Previous media coverage made some organisations wary of who we were, why we were doing the work and its purpose. Similarly, there were understandable concerns around confidentiality, particularly in cases that were still ongoing and cases that were yet to come to court.

Project Violet had already identified a possible thirty-three cases of abuse related to accusations of "possession" or "witchcraft" since 2000. We were given access to these crime reports and after examining them we included fourteen of them that were directly relevant to this report. In the other nineteen cases the information did not show the link to "possession" or "witchcraft" with sufficient clarity for the case to be included. We then tried to identify other cases within and outside London. For ease of comparison we concentrated on cases that had been reported since January 2000.

Each London Borough in which there was a known case was asked whether any social worker had dealt with similar cases within the Borough. We also approached all forty-three police forces in England and Wales via the Association of Chief Police Officers' (ACPO) intranet site. Particular forces with diverse communities were contacted directly and asked to search their force crime and intelligence systems. We also consulted several head teachers in areas where there were known cases to establish whether cases came to light via schools. 


\section{INTRODUCTION}

A number of non-governmental organisations in London were approached. Although based in London, these organisations receive calls for advice from across the country. Some groups were new contacts while others had already been identified during Project Violet and the Community Partnership Project. Attempts were also made to contact groups outside London predominantly in areas of diverse communities as identified by the Institute for Public Policy Research report ${ }^{4}$.

The cases identified may be biased towards the Angolan and Congolese communities because much of the previous research published in the UK, France and Belgium has focussed on beliefs from Congo, Angola and the DRC.

\section{The result of our search for cases was as follows:}

- A total of 93 possible cases were found and reviewed

- Of these cases 19 were rejected as irrelevant and a further 36 were rejected because there was insufficient documentation to be sure they were not double-counted

- There were 38 cases with sufficient information for analysis involving 47 children.

The ninety-three cases came from the following sources:

Thirty-three crime reports were made available by the police that they thought might be relevant to the report. On analysis of the crime reports fourteen were clearly related to "possession" and "witchcraft".

A further twenty-four cases were subsequently identified from social care, police and schools. The majority of cases identified through public sector agencies could be distinguished using names and dates of birth - the remainder could also be differentiated by other unique features. This eliminated the risk of double-counting.

A further possible thirty-six cases were brought to our attention by nongovernmental organisations. However, because we were unable to establish names and dates of birth for this group it was unclear whether they were all new cases.

\footnotetext{
${ }^{4}$ Beyond Black and White - mapping new immigrant communities: Institute for Public Policy Research, Sarah Kyambi, 2005.
} 


\section{INTRODUCTION}

Therefore, in this report the total number of cases analysed is thirty-eight and the total number of children involved is forty-seven. This reflects the fact that five families have more than one child involved in the case.

On some occasions, children do not always appear as statistics in the charts because so little is known about them. For example the exact age is not known of four of the children. In some cases, a social care service may have responded to state that they have a case that fits into this profile but as yet have not supplied all the required data (two children). In other cases, the referral is current and therefore little information is available - and even at the time of writing other cases are coming to light. Where it is thought significant, charts have a bar representing "unknowns" otherwise the charts only include known data. 


\section{CASE ANALYSIS}

\section{Cases identified per year}

The main feature about the chart below is the number of cases identified in 2005. As this issue has been the focus of so much attention recently and this research actively looked for cases, it is unsurprising that more cases were

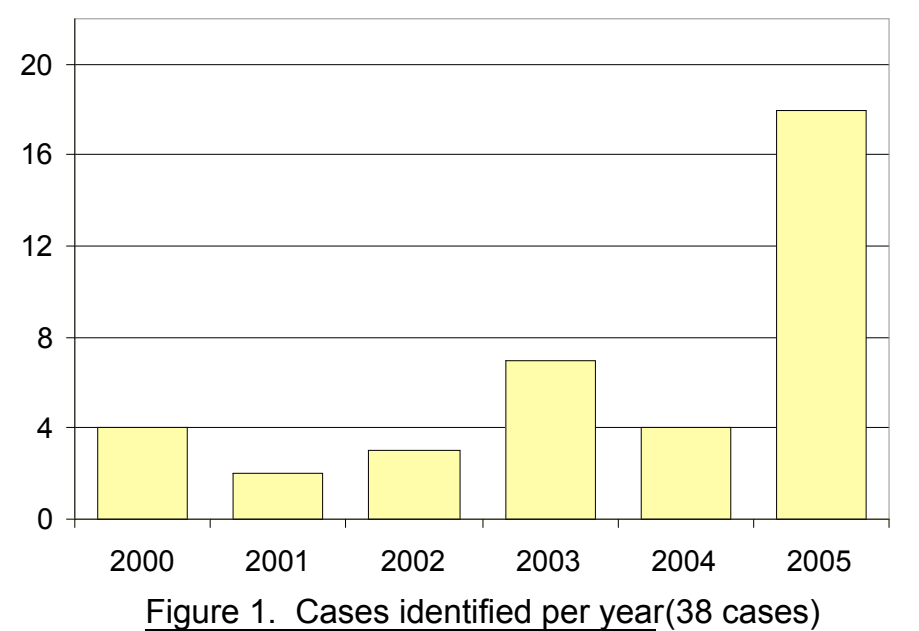

found and are now being recognised. During the four months available for this report, 24 new cases were found. Cases are shown in the years in which they came to notice.

It is often the case that when a particular type of abuse starts to be openly discussed and awareness is raised, more incidents will be recognised.

\section{Victims' age and gender}

In the cases seen, gender does not appear to play a significant role. Boys and girls are equally at risk from this abuse. However, the majority of children came in the $8-14$ age range. It is impossible to judge whether the incidents of abuse stop after the age of 14 years old. Equally, it may be that children find another way of dealing with the abuse ${ }^{5}$ - for example they may run away or they may be

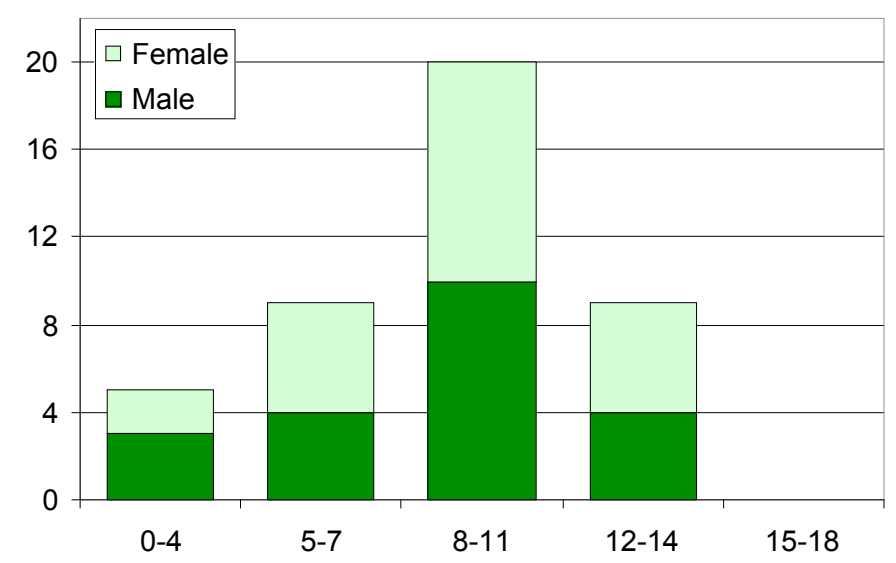

Figure 2. Victims' age (years) \& gender( 43 children) able to defend themselves. It could be that this research simply did not find any cases of children over 14 years old.

What is known is that people of any age can be accused of "witchcraft" or "possession" so it is unlikely that abuse stops at 14 years old.

\footnotetext{
5 "Safe and Sound, Still running II" by Gwyther Rees and Jenny Lee, The Children's Society October 2005
} 


\section{Identifying agency}

Schools appear to be the main source of referrals. There are possibly a number of reasons for this. Firstly, children who attend school regularly usually build a rapport with a teacher and may either give an indication of a problem at home or feel safe enough to disclose abuse. Also a teacher may recognise early signs of distress such as depression, withdrawal and general neglect.

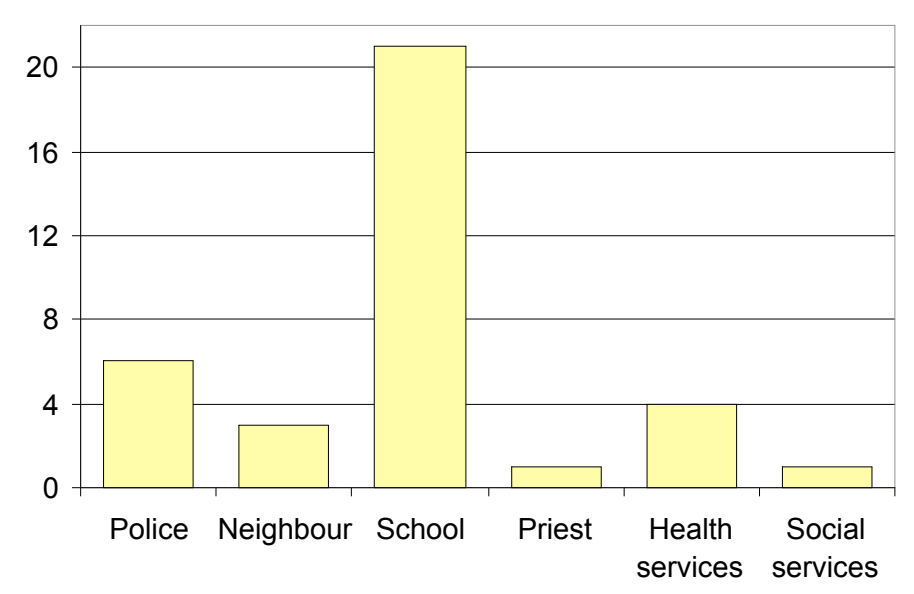

Figure 3. Identifying Agency(36 cases)

In contrast, the families in these cases are less likely to have a relationship of trust with police and social care. These agencies usually become involved when the situation has escalated. For many families, turning to the police or social care is a last resort.

This raises concerns for children who arrive in the UK and are not enrolled at a GP surgery or in a school. This takes away important avenues to identify and prevent cases. It is perhaps also relevant that, as will be seen in figure 12 , it is not uncommon for a family who are abusing their child in this way to remove the child from school - again cutting him or her off from one of the their main sources of protection.

Children who were abused following accusations of "possession" or "witchcraft" showed behaviour consistent with distress. They frequently appear isolated, quiet, withdrawn and sad. For this reason, a significant number of them (twenty) came to attention via their teachers who noticed signs of neglect. Some of the children came to school hungry and brought no food with them. Others were described as unkempt and uncared for - with dirty, unlaundered clothes. Some children came to attention because of their injuries. Two children were excluded from school for aggressive behaviour and two came to attention for truanting. 


\section{CASE ANALYSIS}

\section{Cases by UK region}

The majority of cases in this report occurred in the London area. However, it should not be considered a London problem - previous research has concentrated on finding cases in London. To some extent this research has also focused on those known cases from London.

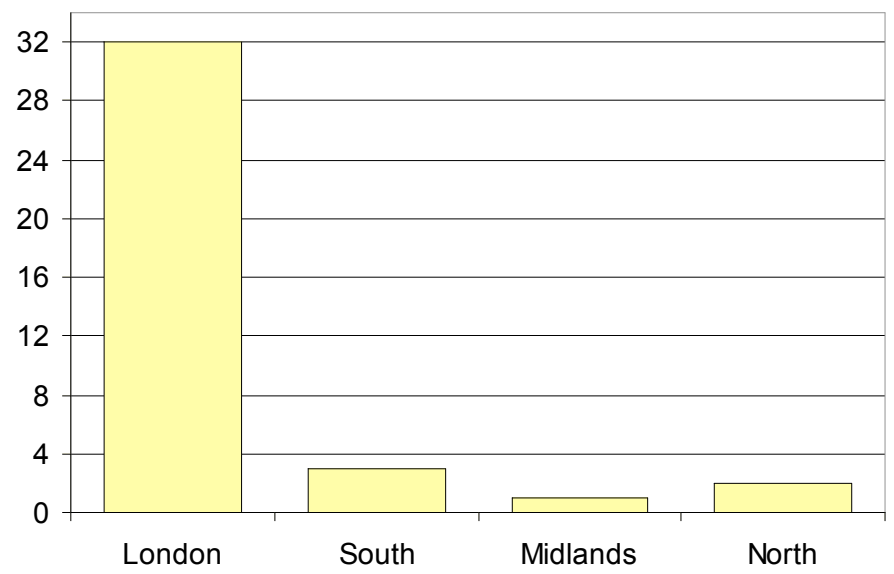

Figure 4. Cases by UK region (38 cases)
During the course of this report, of the 24 new cases identified, a quarter were from outside the London area.

\section{Origin or background}

The research tried to assess the nationality and background of both the victim and the parents or carers. This was extremely difficult as it was rare for the nationality of the parent or carer to be recorded in case files.

From the information that was available it appears that children were with adults from the same background. This chart shows the background of the children. While there is a significant cluster from the DRC, again this may reflect previous work on this community.

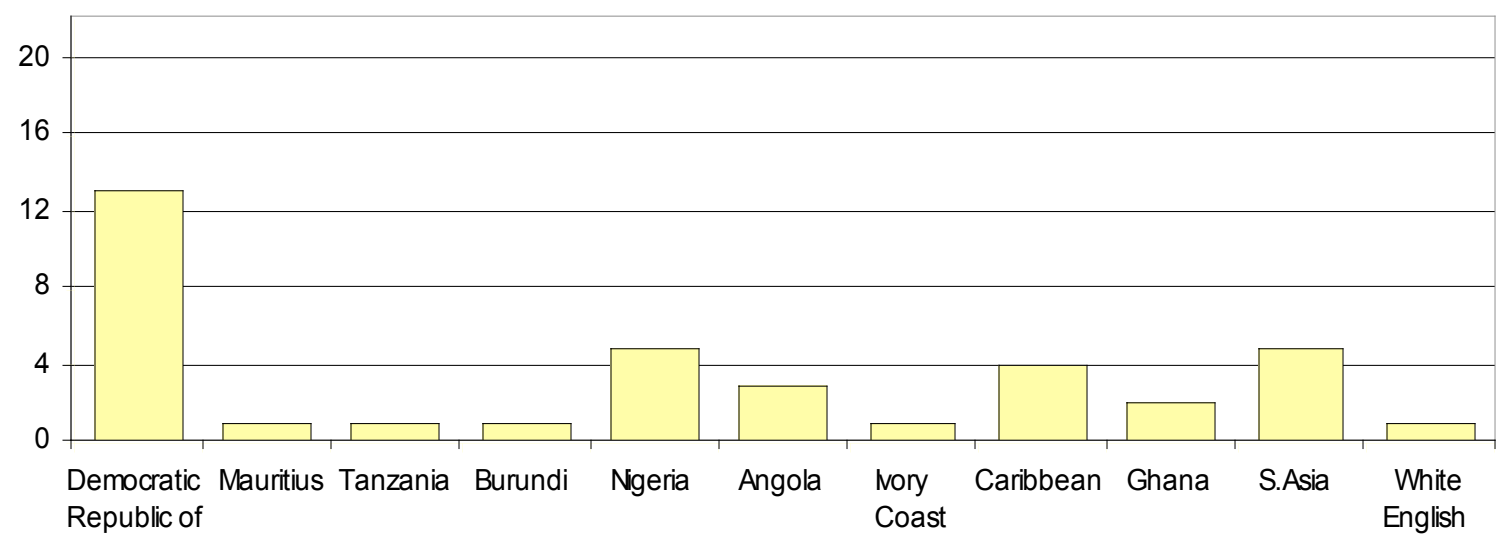

Figure 5. Origin / background (37 cases) 


\section{Period of UK residency}

There is a perception that abuse related to accusations of "witchcraft" and "possession" is more common amongst new immigrant communities. It is

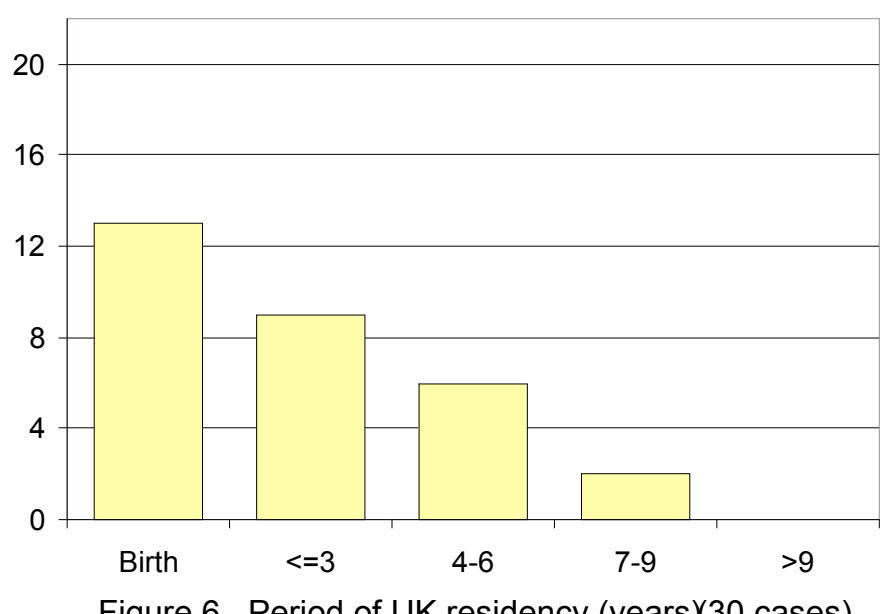
interesting to note that about half the children in the cases were born in the UK.

The ages of those born in the UK range from $2-14$ years old with six being between 8 and 14 years old.

\section{Religion}

The research tried to establish the religion of the families involved but again this was difficult, as religion was not usually recorded in the case notes. Of those that were recorded, the majority described themselves as Christians.

The case that is classified as "mixed" indicates a particular carer who alternated between faiths. The number of families whose religion is not recorded means that it is not possible to make an assessment of the role of particular religions.

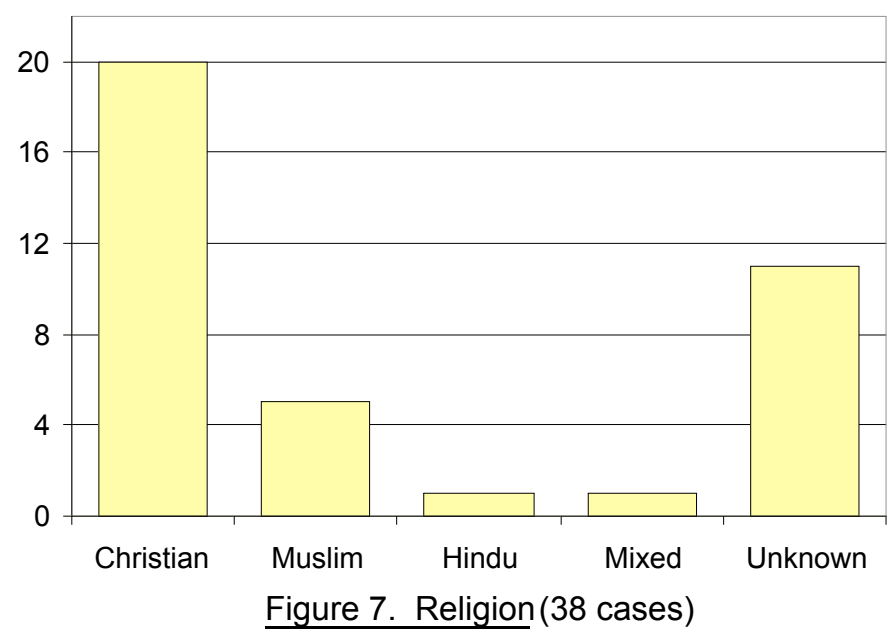

All the cases that were not Christian were identified during the four-month period of this research. This may suggest that so far the emphasis has been on particular communities and so gathering more information may throw up cases across many religions. 


\section{Place of worship involved}

The term "involvement" is used to show an identified connection between the carer and a place of worship, a connection that was reported as having an

influence on the case.

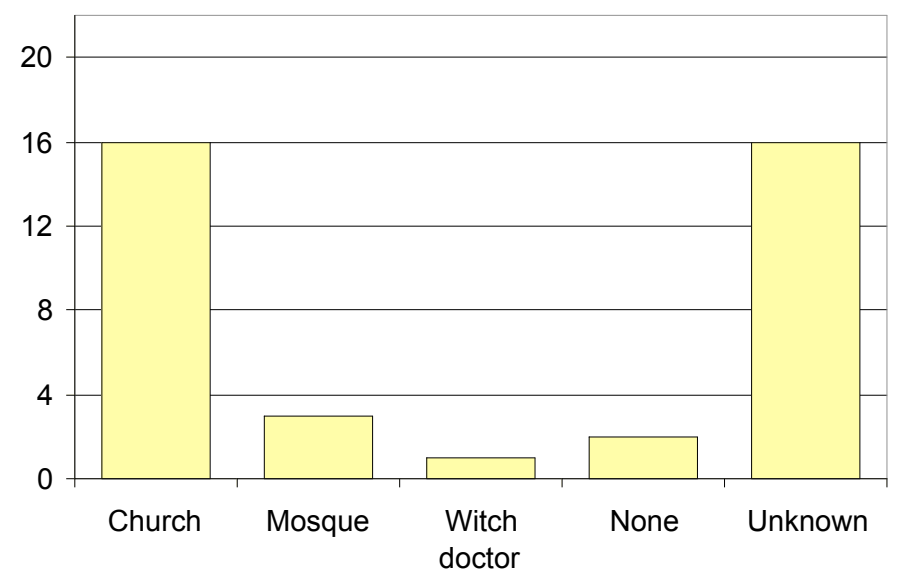

For example a request for an exorcism for a child, a religious leader diagnosing a child or fasting for him or her.

Figure 8. Place of Worship involved(38 cases)

\section{Family structure}

In many cases the relationship between the child and the carer was unclear because in many cultures the head female in the household is called "mother" and the head male, "father"; other adults may be called "aunties" and "uncles".

Further, the true relationship was not always clearly recorded. We were able to establish that in six cases the children lived with both their natural parents. In nineteen cases there was a stepparent or carer in the household who was not related to the child.

The category of "other" includes a range of specified relationships such as

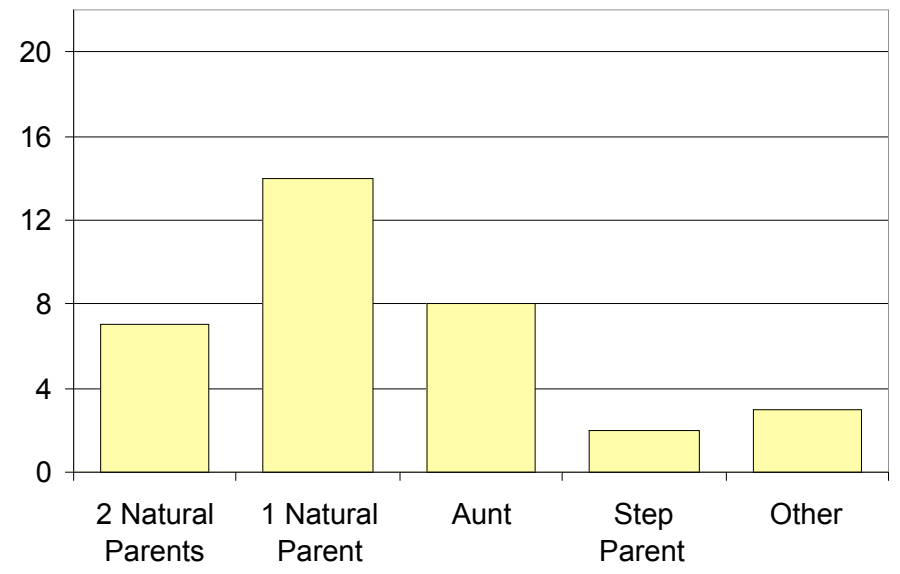

Figure 9 . Family structure(34 cases) children being cared for by siblings, uncles and guardians.

(Note: The categories used in figure 9 are those used in the public sector records and are not relationships that have been verified.) 


\section{A child with a difference}

A common feature between some of the cases was that the carers found it difficult to accept a child with certain characteristics or behaviour. They rationalised these traits as being a sign of "witchcraft" or "possession". These traits included disability and illness, challenging behaviour, sleep walking, wetting the bed and having bad dreams. Commonly these dreams are described as taking the shape of an animal and flying to other parts of the world to kill and eat people.

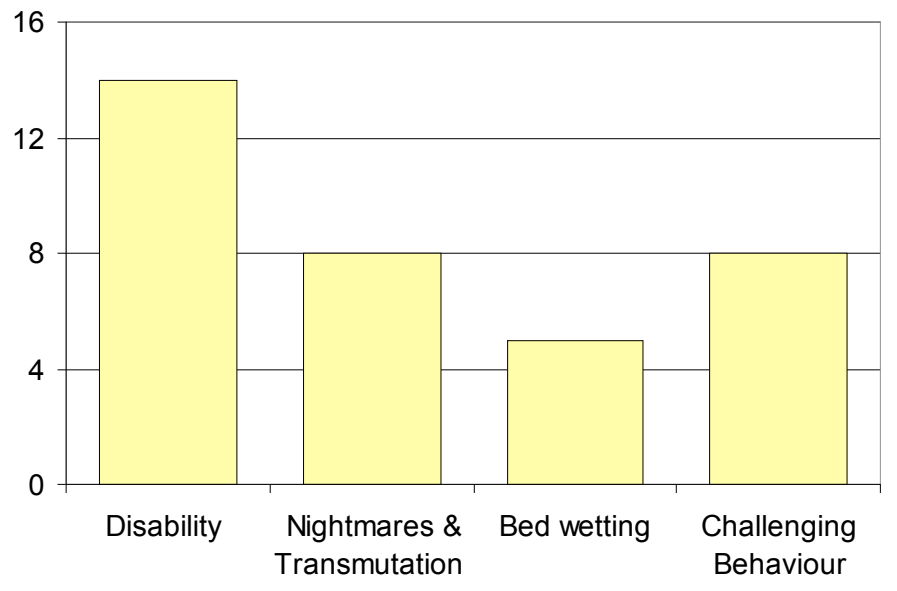

Figure 10. A child with a difference (22 cases)
Note: Some children exhibited various characteristics and behaviours and appear in the chart a number of times.

\section{Accusation}

Every child in this report had an accusation of "evil" made against him or her although the precise language may vary. In addition, when a child is accused of "possession" or "witchcraft", it is commonly accompanied by a belief that they can "infect" others with this "evil".

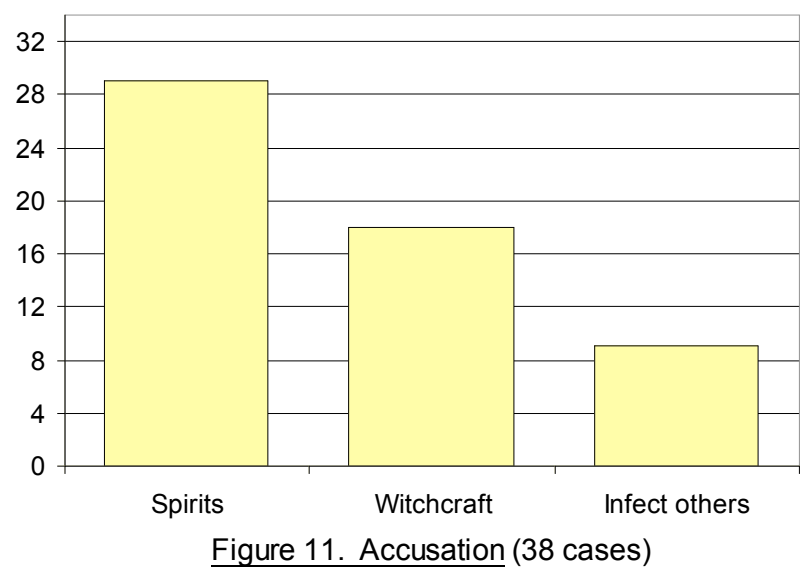

Note: Some children received various accusations and appear in the chart a number of times. 


\section{CASE ANALYSIS}

\section{Types of abuse}

There are various forms of abuse involved in ridding a child of an "evil spirit". In these cases, they ranged from neglect to severe physical abuse including beating and burning. The way in which the "evil spirit" is removed may have different rationales and may vary according to the culture or religions of the family involved.

The chart shows the incidence of some of the forms of abuse. Neglect and beating feature prominently. Two more unusual actions that were regularly reported were - "threat of abandonment" and "wanting the child removed". Nine carers asked social workers to take the child into care, others spoke of taking a child overseas for an exorcism; from which it was unclear whether the child would return. Some simply threatened to abandon the child overseas.

Some children were not allowed to eat meals with the family and suffered longterm malnutrition, others had to prepare food for themselves. There were cases where children were made to fast for up to three days. Others were systematically starved. One of these children lost half its body weight. Two children were taken overseas and it is unknown whether they suffered other types of abuse.

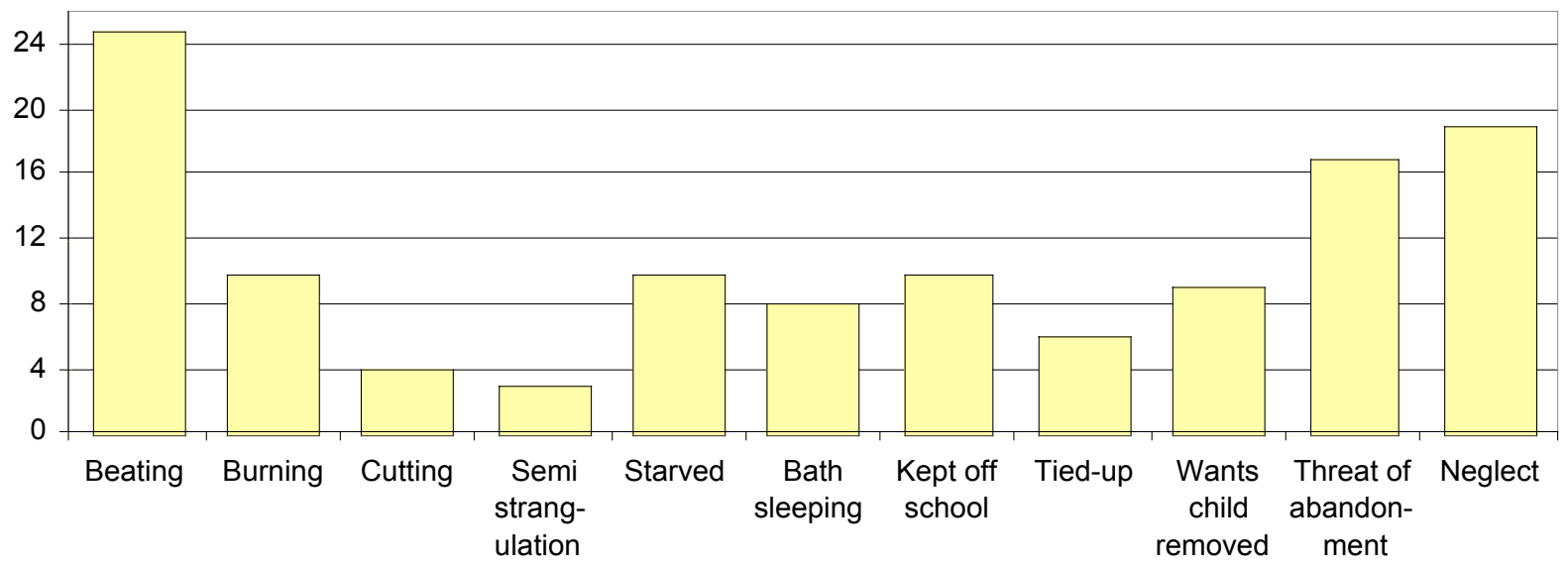

Figure 12. Types of abuse(36 cases)

Note: Some children suffered several forms of abuse and appear in the chart a number of times. 


\section{CASE ANALYSIS}

\section{Outcomes}

Eighteen children who had been abused following an accusation of "witchcraft" or "possession" were placed in long-term foster care. Two were placed in secure care. A further twenty-three of their siblings were also placed in foster care even though they had not been accused. This chart includes the outcome for other siblings.

Four children returned home with no further action taken and seven were returned home and placed on the child protection register or under a supervision order.

Ten children were taken overseas and nothing further is known.

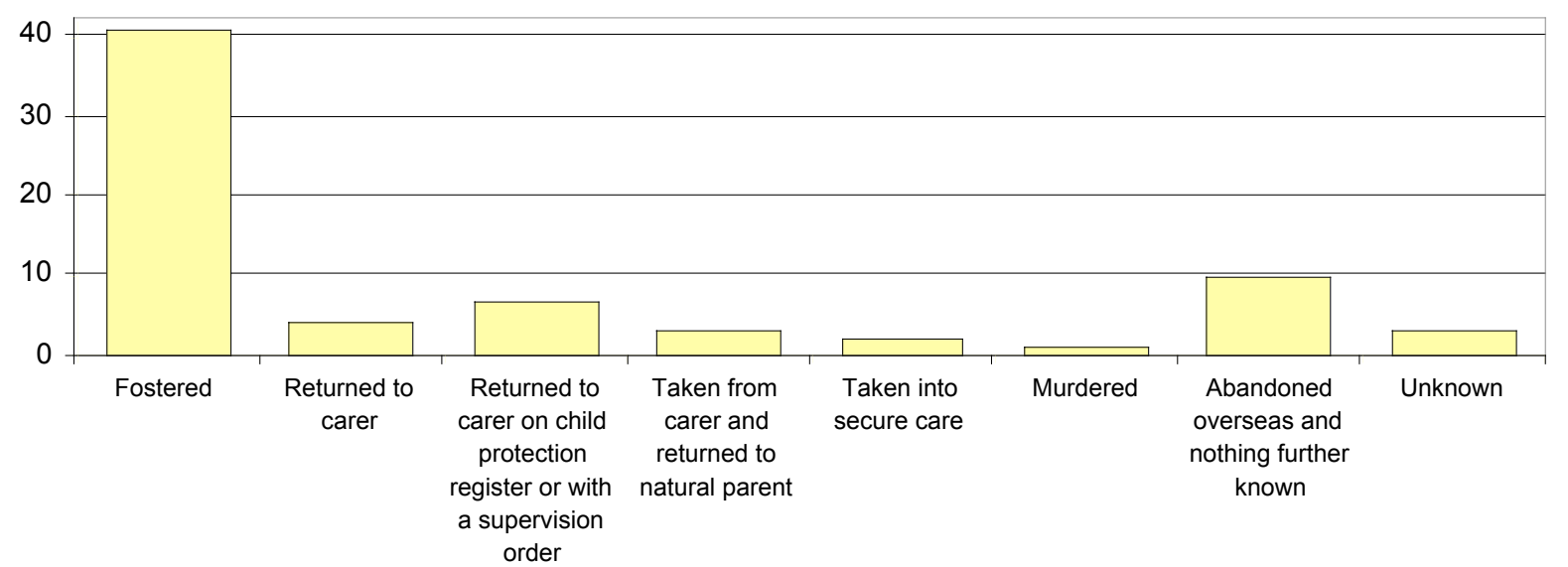

Figure 13. Outcomes (71 children) 


\section{FINDINGS}

Given the constraints of the time available together with the scarcity and confidentiality of the facts, this report does not claim to be a full account of child abuse in England linked to accusations of "possession" and "exorcism" but simply the report of a first reconnaissance. Even so, there is sufficient information to hand to identify significant features of this form of child abuse and to set out the steps needed to begin to reduce the number and severity of the cases that occur.

The main common features that appeared from the desk research and the case analysis are:

- Family structure

- A child with a difference

- Disability

- Scapegoats

- Types of abuse

- Outcomes

- Case handling

- Migration

- Mental health

- Religious and spiritual beliefs

- Movement of children 


\section{FINDINGS}

\section{COMMON FEATURES BETWEEN CASES}

\section{Family structure}

One of the notable features surrounding family structure was the difficulty in understanding the relationship between the child and the carers.

The family structure tended to be complex. Children lived with "mothers", "fathers", "aunts", "uncles", siblings and half siblings all in the same household it was difficult to establish whether the carers were related to the child or whether it was a private fostering arrangement ${ }^{6}$. Carers often had partners who were transient or several partners - some appeared to be polygamous marriages. The information about relationships was often conflicting.

In some cases immigration status and benefits depended on the child being with a natural parent. Children therefore did not disclose the real relationship. In one case DNA was used to establish if the child and carer were related.

Research suggests that children become more vulnerable to accusations of "possession" and "witchcraft" if there is a change in family situation or there is no bond of affection between the carer and child. Carers may have developed a strong family relationship prior to the arrival of the child or the remaining natural parent may form a stronger bond with a new partner and their subsequent children. At least five of the carers were pregnant at the time of the abuse.

At least twenty-five of the children had siblings or half siblings in the household. In three cases, two children in the same family were accused of being "possessed". In all the other cases one child was singled out and accused.

\section{Scapegoats}

The change in family situation or a change of circumstances for the worse, may lead to the isolated, more vulnerable "outsider" being blamed. The work of Tom Douglas ${ }^{7}$ on scapegoats as cited in Working with Black African Children and Families $^{8}$ is relevant.

"The main factors influencing the selection of the "scapegoat are":

- The relative powerlessness of the child vis-à-vis the parents

\footnotetext{
${ }^{6}$ A privately fostered child is one under 16 (or under 18 if disabled). The child receives care and accommodation continually for 28 days or more by someone who is not a parent, does not have legal parental responsibility and is not a close relative. The Children Act 2004 defines close relatives as parents, stepparents, grandparents, siblings, aunts or uncles.

${ }^{7}$ Scapegoats, Transferring Blame: Tom Douglas, Routledge, NY, 1995.

${ }^{8}$ Working with Black African Children and Families: Amma Anane-Agyei, Learning Design Ltd, London, 2001.
} 


\section{FINDINGS}

- The need to choose someone who was not performing any essential family role

- The need to choose a person intimately related to the sources of the tension

- The choice should be able to symbolise the conflict by, for example

- A lack of achievement, failure

- Acting independently and violating the family norms of loyalty

- The choice usually had suffered serious physical disease when young or had a striking physical abnormality".

\section{A child with a difference}

The reason why a particular child is singled out and accused of being "possessed" or being a "witch" is difficult to ascertain. Our desk research suggests that several factors combine to make a child more at risk. These include rationalising misfortune, a change of circumstances for the worse, a child with a "difference" and a weak bond of affection between the carer and the child.

It is human instinct to try to rationalise misfortune - whether it involves seeking a medical, scientific, religious, mystical or spiritual explanation.

In the cases we have seen, rationalisation often takes the form of believing oneself to be cursed, to be the victim of black magic, voodoo, witchcraft, obeah or believing that someone else is "possessed by evil spirits".

When family troubles begin or are exacerbated - serious illness, financial troubles, unemployment etc - people may look for anything that is new or "different" as the cause of the problem. It may be a child who has recently joined the family or a child with a "difference" that is blamed and becomes a scapegoat.

Research ${ }^{9}$ suggests that when a family experiencing problems has a child who exhibits a behaviour that the family views as problematic, difficult to understand or outside the family norms; this, combined with a change in family dynamics may increase the risk of the family accusing the child of harbouring some "evil" force such as "witchcraft" or "possession".

The behaviour that carers view as challenging includes rebelliousness, disobedience, independence, defiance and developing and establishing individuality. Many of the children were described by their carers as "naughty".

\footnotetext{
9 "Enfants Sorciers en République Démocratique de Congo" September 2005, Javier Aguila
} Molinas, Save the Children UK 


\section{FINDINGS}

\section{Disability}

Children with a disability were also viewed as "different" and their disability may be explained away as "possession" or "witchcraft". We were able to establish that fourteen of the children had some degree of disability, imperfection or blemish. This could be as mild as a stammer or a severe mental and physical disability. These were:

- Epilepsy (2)

- Stammer (2)

- Deafness (1)

- Learning disabilities (4)

- Autism (2)

- Mental health issues (4)

- Life limiting illness (2).

This suggests that carers might view any illness or disability as a sign of "possession".

Interestingly, three of the children were described as exceptionally bright which could have been the reason for them standing out as "different".

\section{Types of abuse}

There were a variety of different types of abuse. There was no evidence that the abuse had the regularity of a ritual.

- Beating

Twenty-four children reported being beaten, kicked, hit or punched. The arm of one child was broken deliberately. Carers often talked about this abuse as "beating the devil out" of the child.

- Burning

Ten children were burned - this involved scalding and burning with an implement. In four cases the children were burned with an iron. Although no carer gave an explanation for burning the child, our research suggested that extreme heat may burn the "evil" out.

- Cutting/stabbing

In four cases children were stabbed - an explanation given for this was "to create a way out" for the "evil".

- Semi-strangulation, applying pressure and smothering Three children reported being semi-strangled. Research suggests this is "to squeeze the life out of the evil". 


\section{FINDINGS}

- Fasted and starved

Ten children described being fasted for various periods of time from fifteen hours to three days. A further two children were starved - one lost half his or her body weight. One child fasted himself or herself in the belief that would provide a cure. The rationale for fasting and starving a child was to weaken the "evil spirit".

- Isolation

Isolation was reported in many cases. The rationale for this was to prevent the "evil" from spreading to other people. This took the form of not allowing a child to eat with the family, to associate with the family, to share a room or have any physical contact with anyone. In one case the carers were so scared of the child they only touched him or her with a stick. Five children were removed from school in an attempt to isolate them further. This prevented them from seeking help. The level of neglect was described as severe in nineteen cases.

- Other abuse

Other forms of abuse included being made to sleep in the bath (two children), being forced to have cold baths, being held under water, being tied or locked up (four children) and having chilli peppers (four children), salt (five children) or ginger (two children) applied to eyes and genitals ${ }^{10}$ (this may be viewed as burning).

In one case a girl appeared to be "groomed" for sexual exploitation.

Four children were reported as hiding, storing or smearing their faeces. Two children were turned away from school for having faeces on his or her clothing.

In two cases, siblings were encouraged to take part in the violence. In several cases siblings were not allowed to talk to the victim.

\section{Outcomes}

Police officers, social workers, teachers and others considered that children who are abused following an accusation of "possession" suffer lasting damage in many areas of their lives. They suffer damage to their physical and mental health, education, ability to form relationships and self-esteem. The victims who are convinced that they are "possessed" may require years of support. Some never recover. In short, their life chances are severely diminished.

When social care did decide to intervene, the child was usually removed from the household and placed in care. In only two of the cases did the carer object to the child being taken. In nine cases the carers specifically asked social care

\footnotetext{
${ }^{10}$ In some cultures applying chilli peppers to parts of the body is considered acceptable chastisement. Therefore the use of chilli peppers does not necessarily indicate that a child is a "witch" or "possessed".
} 


\section{FINDINGS}

to take the child into care. Eighteen of the children accused of being

"possessed" have been taken into long-term care. Twenty-three of their siblings were also taken into long-term foster care.

In each of those eighteen cases the professionals involved stated that there was a weak bond of affection between the carer and the child. In only one case has there been on-going contact between the carer and child since their separation.

In a further ten cases the child was taken overseas and their whereabouts are unknown. Half of them went for a specific purpose such as "traditional treatment" or an "exorcism"; four of them are known to have been abandoned. Two attempted to seek help to return to the UK but were not British nationals.

\section{Case handling}

Throughout the research of this report, it became apparent that there were variations in the way that public sector agencies handled these cases.

The accusation of "possession" or "witchcraft" frequently went unrecognised or the child was thought to be "making it up".

A lack of understanding around the issue and sometimes failure to apply existing best practice led public sector professionals to act in a way that was not always in the best interests of the child.

In one case, a child was returned home for family counselling even though the carer asked for the child to be removed. In another case, the social worker had never visited a child, even though it was known that the child had been taken to various places of worship for a "cure" and there had been a threat to take the child overseas. One child was never spoken to alone. On another occasion a social worker left a child in the presence of his or her carer while the child was awaiting a medical examination following a severe physical assault by that carer. The child later withdrew all allegations and returned home.

Schools were able to identify children suffering abuse at an early stage but in some cases the level of abuse did not reach social care threshold criteria for engagement. Children were left with or returned to carers with no further action.

When cases are identified, there are still occasions when public sector agencies fail to implement multi-agency procedures, for example attending joint home visits, attending strategy meetings and maintaining good communication between agencies. 


\section{FINDINGS}

Migration

One case involved a white English family. All the other families were first or second generation migrants.

It may be that the predominance of cases in this report involving first or second generation migrant families does not so much concern their cultural background but the additional stresses placed on families adjusting to migration.

It is well documented that migrating families face particular difficulties. These include isolation from extended family, a sense of not belonging or feeling threatened, misunderstood and confused. The expectations associated with migration, such as the quality of life, levels of income and ability to help relatives overseas financially may not be fulfilled. Other stresses include continuing uncertainty around immigration status, being unable to work, living in inadequate housing and not receiving the recognition of status, value or worth that they held in their home country.

Many major changes, particularly those resulting from migration, can cause significant stress to individuals especially those trying to manage conflicting identities. In some cases this can go so far as constituting an actual mental health problem ${ }^{11}$.

\section{Mental Health}

In eleven cases it was reported that there were concerns for the mental health of a carer. The illnesses involved included post-traumatic stress disorder, depression and schizophrenia ${ }^{12}$. One carer starved himself or herself to death for which the child was later blamed by the surviving carer. Three carers were sectioned under the Mental Health Act.

The carer often genuinely believes the child has been completely taken over by, the "devil". In the perpetrators' minds any abuse is not going to affect the child because the child is effectively not there anymore - any violence is directed at the devil. Although it is helpful to understand the context, this in no way excuses the abuse.

Public sector professionals acknowledged that they had difficulty in understanding that some carers truly believed that a child could be "possessed". They had even more difficulty in understanding the belief that a child was so "evil" that the carer's life might be in danger. Some may assume that those holding this belief must have a mental illness. Some carers were sectioned under the Mental Health Act while others were prosecuted.

\footnotetext{
${ }^{11}$ Clinical Practice and Epidemiology: Mental Health Journal vol. 1:13 2005 Report on Mental Health in Europe Working Group (Carta M.G, Bernal M, Hardoy M.C, Haro-Abad J.M.)

${ }^{12}$ www.doh.gov.uk "Delivering race equality in mental health care" press releases 04/07/05 and speech by Rosie Winterton, Minister of State for health 03/11/05 to EU Presidency at the launch of the EU green paper on Migrant Mental Health.
} 


\section{FINDINGS}

\section{Religious and spiritual beliefs}

In all the cases reviewed the carers held the belief that the child was a "witch" or "possessed". This belief is widespread in many cultures and religions.

The scarce information available in case reports about the role of places of worship means that our findings in this area are limited.

We did establish that five children alleged being beaten in a place of worship. Two children were taken to "various" mosques but it was not clear what happened at the Mosques. One child was diagnosed in a mosque. Two children were taken to church for an exorcism - the details of these were not available. A further child was diagnosed in a church. On one occasion a priest referred the case to child protection agencies.

In three cases carers are known to have paid for help from places of worship or witchdoctors. The vulnerability of these families may make them susceptible to exploitation.

In seventeen cases it was unknown whether a place of worship was involved. It is not clear whether this means the abuse occurred entirely independently of the involvement of the place of worship or simply that the question was not asked.

We found that different terms are used in different religions. In Muslim cases the "evil" may be referred to as "possession by evil spirits", "the Evil Eye" or "Djinns". In the Hindu case the terms "possession" and "bad spirits" were used interchangeably. In the Christian cases a variety of terms were used including devils, snakes, voodoo, curses, demons, evil spirits, and witches.

\section{Movement of children}

Through the course of this report it has become apparent that children including unaccompanied minors can travel internationally and nationally with considerable ease in a way that is very difficult to monitor. This lack of monitoring can increase their vulnerability - few, if any, checks are made on any adults they are with, where they are to reside in the UK and whether they are registered in school or with the health service.

It was also common for children to move schools regularly. Sometimes this appeared to be in connection with an investigation carried out by Children's Social Care. It was not clear whether this was a deliberate attempt by the carer to avoid close scrutiny. 


\section{GOOD PRACTICE}

\section{GOOD PRACTICE}

During the course of researching this report some areas of good practice were identified. Some examples of this good practice include:

\section{Early intervention}

Social care threshold criteria for engagement are often too high to pick up this type of abuse at an early stage. In practice this means that when a case comes to light early and the child is referred to social care, social care is not in a position to act.

There are some non-governmental and faith based organisations who work with families who are struggling to adapt to life in the UK. These organisations give advice about a range of issues including child-rearing practices, illness, housing, immigration status etc.

Migrant families are more likely to turn these organisations for support than to public sector agencies. They are more likely to discuss openly cultural and belief issues without fear of being misunderstood. These organisations often see struggling families at an early stage. At this early stage, it may be possible to change the carer's response to the child by helping them to view the issue in the wider context rather than simply as a problem of "possession" or "witchcraft". These organisations can prevent cases escalating by making early referrals and interventions to public sector agencies.

In London there is a non-governmental organisation with a network of therapists working in schools alongside children with behavioural problems. The children often disclose abuse and neglect and several have revealed accusations of "possession" or "witchcraft".

Some local authorities with diverse populations e.g. Tower Hamlets, Southwark, Hackney, Haringey, Enfield are making efforts to find out more about their local non-governmental and faith based organisations and to work more closely with them on child protection.

\section{Experience in France and Belgium}

In some cases, assisting the family to resolve their problems diminishes the likelihood of the family blaming a child for the problems. Dr. Ezembe from Afrique Conseil in Paris cited an example of a family with problems concerning their visa. They had decided their stepdaughter, recently arrived from overseas, was a witch blocking their progress and had started to mistreat the girl. When Dr. Ezembe's staff were able to solve the visa problem the family decided that the problem had not been the daughter at all but probably had been a jealous brother overseas and relations with the girl normalised quickly.

A similar example from France concerns a case where the stepfather began mistreating a girl believing her to be a witch and the staff at Afrique Conseil arranged for the girl to go and stay with a third party for a while until the 


\section{GOOD PRACTICE}

situation had calmed down and they had been able to help the stepfather find another way of looking at his problems. This reflects the Congolese family background of that case whereby it is very normal when relations are strained in a family to send the child away for "a breathing space". In the Western European context this extended family network to provide a break does not exist and for a child to be fostered or taken into care by social care is usually not viewed in this light but rather as a failure or a shame.

\section{Child protection in places of worship}

The Churches' Child Protection Advisory Service (CCPAS) provides literature and training on all aspects of child protection including exorcism - termed "praying for children". CCPAS encourage and facilitate churches to undertake criminal record bureau (CRB) checks on their staff. They publish a quarterly magazine called, Caring, which looks exclusively at child protection issues within churches. They also provide DVDs, videos and training on child protection in churches. They recently held a conference with pastors from majority black churches. This was positively received as they "felt they had been marginalised and excluded, partly because of the press publicity".

African Caribbean Evangelical Alliance (ACEA) in partnership with Churches Together in England (CTE) held a conference on black majority churches looking at a range of issues for their churches today including child protection and interaction with local authorities. ACEA also have a minority ethnic Christian affairs working group looking into this issue in partnership with a child protection non-governmental organisation and with local authority agencies. ACEA, the Metropolitan Police Service, Local Authorities and CCPAS held a conference with pastors from the community to address the issue of child protection in churches and specifically dealing with children accused of "being possessed" or "witches". ACEA also require churches wishing to be a member of their alliance to have child protection procedures in place and for church staff to have undergone CRB checks.

The Muslim Parliament organised an interfaith conference to consult on good practice in tackling child abuse and from this has drawn up and circulated guidance in conjunction with Kirklees Council ${ }^{13}$ for the Muslim community.

\section{Specialist training and support}

Tower Hamlets has held a series of workshops and produced a handbook to assist social workers dealing with black African children and families. Hackney held a Serious Case Review of a case involving "witchcraft" and "possession". The outcome was that they have changed their assessment criteria for families when this belief is a factor in the abuse. A French consultancy, Afrique Conseil also provide specialist training days for French social workers dealing with black African families. They complement this with parenting classes for recently arrived migrant families.

\footnotetext{
${ }^{13}$ Safe Children Sound Learning - Guidance for Madressahs', published by Kirklees Metropolitan Council Education and Social Services, 2004.
} 


\section{CONCLUSIONS}

\section{CONCLUSIONS}

The number of cases of child abuse linked to accusations of "possession" and "witchcraft" are small compared to the total number of children known to be abused each year.

There were difficulties identifying cases. The difficulties included lack of awareness, concerns around confidentiality, reluctance to share information and poor record keeping.

The belief in "possession by evil spirits" and "witchcraft" is widespread.

The belief is not confined to particular countries, cultures or religions nor is it confined to recent migrants.

The abuse occurs when the carers attempt to "exorcise" the child.

There are various social reasons that make a child more vulnerable to an accusation of "possession" or "witchcraft". These include family stress, a change in the family structure, disability, a child with a difference and a weak bond of affection between the carer and the child.

The role of places of worship in these cases is unclear.

The effect on the family and the victim are devastating. The children and their siblings invariably need long-term foster care.

Police and social workers are not able to change the beliefs of carers.

Schools and non-governmental organisations appear to be in the best position to identify abused children at an earlier stage. Children tend to come to the attention of police and social care after the abuse has escalated. Early intervention may prevent repetitive abuse. There are variations within public sector agencies in the way that cases are handled. Some professionals were more aware of the signs than others. 


\section{RECOMMENDATIONS}

\section{RECOMMENDATIONS}

It is recommended that:

\section{Central record of cases}

Information about this type of child abuse should be collated centrally. This would provide a clear national picture of the scale and extent of the problem. This could be managed by DfES or police and should be maintained for at least three years. The information for each case in the record should be compiled in a standardised form that is easily retrievable for everyone that has a legitimate need for access.

Contact details of professionals familiar with dealing with these cases could also be held centrally. They could then provide support to police officers, social workers, teachers and other professionals less familiar with handling this type of case.

\section{Practice guidance}

DfES, social care, police, schools and immigration should combine in preparing "good practice" guidelines for handling these cases. The guidance should include information on:

- Early intervention

- Reporting cases

- Liaison between public sector agencies, non-governmental organisations, faith based organisations and places of worship

- Confidentiality and information sharing

- Risk factors

- How to handle cases.

\section{Movement of children}

Better information about children moving in and out of the UK is required. The Immigration Service should work with public sector agencies to protect children at risk that pass through immigration controls ${ }^{14}$.

${ }^{14}$ Operation Paladin Child 12.7.04 Metropolitan Police Authority 


\section{RECOMMENDATIONS}

\section{Working with non-governmental organisations}

Non-governmental organisations working with some of these families are effective but lack resources. In order to assist early intervention in cases, Local Authorities should develop links with these organisations with a view to offering support, training and funding.

\section{Child Protection in places of worship}

Places of worship need child protection procedures in place together with information about good practice in "praying for", "delivering" or "exorcising" children. Local Safeguarding Children Boards (LSCBs) should identify places of worship within their area and build links with them in order to monitor effective child protection measures. 


\section{GLOSSARY OF TERMS}

\section{Glossary of Terms}

The definitions used here have been taken from a variety of sources including the Oxford English Dictionary, the free dictionary (online), Wikipedia (online), and specialist websites. They give a broad overview of the concept and are not intended to be prescriptive.

\section{Black magic}

Black magic is the branch of magic (paranormal power) dealing in death, destruction, manipulation and spells.

Djinns (alternative spelling Jinn or Jinni from which is also derived genie) Jinn are beings much like humans, possessing the ability to be good and bad and believed in some cases to be able to possess a person. According to many Islamic scholars, the Devil was a jinn, although others stress the difference between Djinn and Qareen, the latter being an evil spirit intent on tricking people into committing sins.

\section{Evil Eye}

The Arabic word al-'ayn (translated as the evil eye) refers to when a person harms another with his eye whether intentionally or not. It starts when the person likes a thing, then his evil feelings affect it, by means of his repeated looking at the object of his jealousy.

\section{Kindoki}

(Ki)ndoki, is a common term throughout West and Central Africa to mean witchcraft in a negative and injurious sense. However this is a simplistic use of a term for a complex and often localised interpretation of the interaction of people with spirits and forces. Other regions of Africa have similar concepts with different names.

Obeah (alternative spelling Obi)

A form of religious belief of African origin, practiced in some parts of the West Indies, Jamaica, and nearby tropical America, involving "sorcery" and often understood in the same way as Voodoo.

\section{Ritual Abuse}

Organised sexual, physical, and psychological abuse, which can be systematic and sustained over a long period of time. It involves the use of rituals, with or without a belief system. It usually involves more than one perpetrator. Ritual abuse usually starts in early childhood and involves using patterns of learning and development to sustain the abuse and silence the abused.

\section{Sorcery}

Belief in magical spells that harness occult forces or evil spirits to produce unnatural effects in the world 


\section{GLOSSARY OF TERMS}

Voodoo (alternative spelling Vodun, Voudoun, Vudu, Vodou)

The term Voodoo is applied to the branches of a West African ancestor-based Theist-Animist religious tradition. Its primary roots are among the Fon-Ewe peoples of West Africa, in the country now known as Benin. The word vodun is the Fon-Ewe word for spirit. Versions of Voodoo have travelled to other areas with the movement of people.

\section{Wicca}

Wicca is a nature-oriented (not nature-worshipping), initiatory, pagan mystery religion based on the traditions and beliefs of tribal Europe, with significant influence from Western magical traditions and a ritual structure based on the writings and practices of Gerald Gardner in the 1940's and the covens of the New Forest region. 
Copies of this publication can be obtained from:

\author{
DfES Publications \\ P.O. Box 5050 \\ Sherwood Park \\ Annesley \\ Nottingham \\ NG15 ODJ
}

Tel: 08456022260

Fax: 08456033360

Minicom: 08456055560

Oneline: www.dfespublications.gov.uk

\title{
(c) Crown Copyright 2006
}

Produced by the Department for Education and Skills

ISBN 1844787354

Ref No: RR750

www.dfes.go.uk/research 